\title{
A LITERARY READING IN THE LINGUISTIC EFFORTS OF IBN QUTAYBA IN HIS BOOK ADAB AL-KĀTIB “THE WRITER'S LITERATURE”
}

\author{
Saleh ABBOUD ${ }^{1}$
}

\section{Istanbul / Türkiye \\ p. 577-586}

Received: 25/11/2021

Accepted: $15 / 12 / 2021$

Published: 01/01/2022

This article has been scanned I iThenticat No plagiarism detected

\begin{abstract}
:
Ibn Qutayba (d. $276 \mathrm{AH}$ / $889 \mathrm{AD}$ ) was attentive in both the Arabic linguistics and its literature, whereas he hath assorted numerous workbooks which testify his care about, and those who came after, have been benefited from his critical material on the fields of language and literature, this incipit of the research is concerned with reading Ibn Qutayba's linguistic views through the subject of his book Adab al-Kātib "The Writer's Literature" particularly those related to orthography and solecism in the Arabs' language, and the importance of the research lies in shedding light on the Arab linguistic legacy in the third century $\mathrm{AH} \backslash$ ninth century AD, and displaying the impact of Ibn Qutayba in it, and the objective of the research is to analyze what was mentioned in two important linguistic topics from the book of Adab al-Kātib "The Writer's Literature" which are: the topic of rectification of the hand and the topic of rectification of the tongue, which they are both linguistic topics that show the prevailing linguistics status in the era of Ibn Qutayba, thence, they are also considered a door to understanding the linguistic opinions that the writer gleaned from his wells and sheikhs.

The research deals with linguistic problems related to the orthography and the Arab solecism and phonetics among the populace in the era of Ibn Qutayba, relying on a research framework that begins with a preamble considering both the writer and the book, and then deals with the linguistics status in the third century AH through what was mentioned in the book's sermon, then he presents some of what was mentioned in his book Adab al-Kātib "The Writer's Literature" in the two chapters; rectification of the hand and rectification of the tongue, then epitomized the disputations between Ibn Qutayba and the commentators of his book regarding the two mentioned sections, and the research is concluded with a brief epilogue that presents his most prominent conclusions.
\end{abstract}

Key words: The Writer's Literature, Ibn Qutayba, The Arabic Language In The Third Hijri Century, Solecism.

http://dx.doi.org/10.47832/2717-8293.15.3

1 (iD) Researcher, Marj Ibn ‘Amer College, Palestine, saleh3abboud@gmail.com, https://orcid.org/0000-0001-9027-4205 


\section{"قراءةٌ في الجهود اللّغويّة لابن قتيبة في مؤلّفه أدب الكاتب"}

\section{2 صالح عبّود}

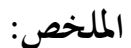

اهتمّ ابن قتيبة (ت. 276هـ/ 889م) بعلوم اللّغة العربيّة وأدمها، وصنّف في ذلك تصانيف تشهد على عنايته بها، وقد أفاد من أتى بعده من مادّته النقديّة في مجالي اللغة والأدب، وتمتمّ هذه الإطلالة البحثيّة بقراءة آراء ابن قتيبة

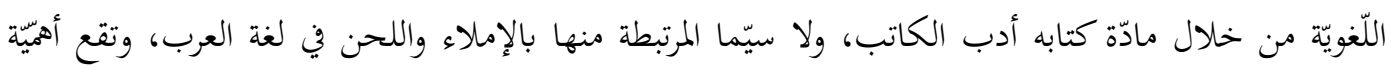
البحث في تسليطه الضوء على التراث اللّغويّ العربيّ في القرن الثالث الهجريّ/ التاسع الميلاديّ، وتبيان أثر ابن قتيبة فيه، وغاية البحث تحليل ما ورد في مبحثين لغويّين هاميّن من كتاب أدب الكاتب هما: مبحث تقويم اليد

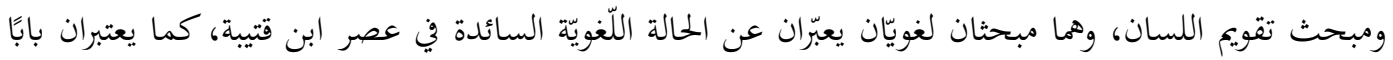
لفهم الآراء اللّغيّة التي استقاها الكاتب من مصادره وشيوخه. يعالج البحث إشكاليّاتٍ لغيّةً ترتبط بالإملاء وقواعده ولحن اللسان العربيّ لدى العامّة في عصر ابن قتيبة، معتمدًا

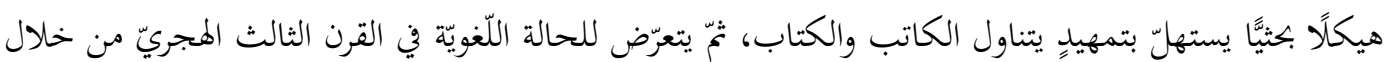

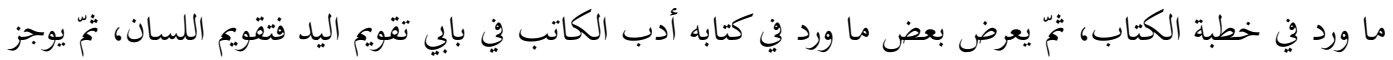

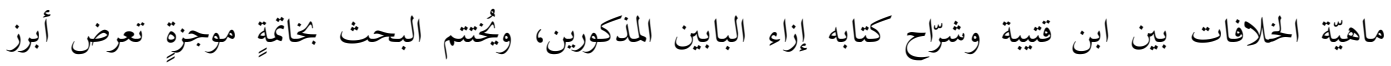

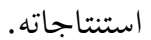
الكلمات المفتاحية: أدب الكاتب، ابن قتيبة، اللغة العربيّة في القرن الهجريّ الثالث، اللحن.

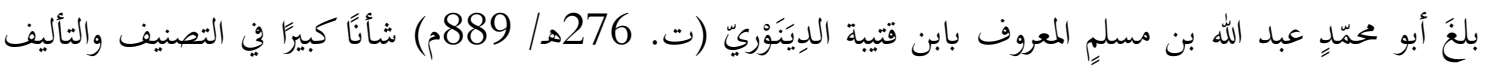

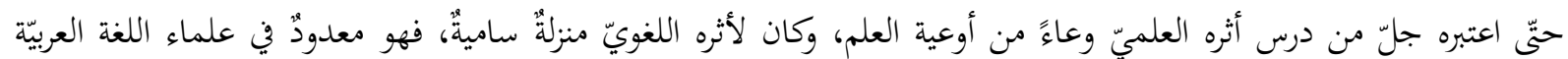

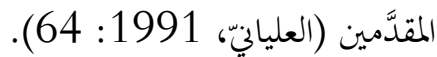

من أبرز شيوخه في النحو واللّغة الإمامين سهل بن محمّد بن عثمان أبو حاتم السِجِسْتانيّ (ت. 250هـ/ 863م)، وأبو الفضل العبّاس بن الفرج الرِياشيّ (ت. 257هـ/ 871م) وهما من المعدودين في علوم اللغة العبيّة ( ابن النديم، 2013 2013: 8687)، وكان من كبار النحاة وأهل اللغة في عصره، وجاء فيه أنّه "كان رأسًا في علم اللسان العربيّ، والأخبار وأيّام الناس" (الذهبيّ؛

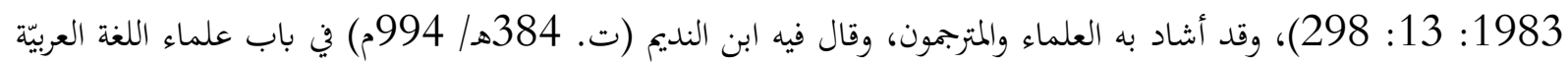

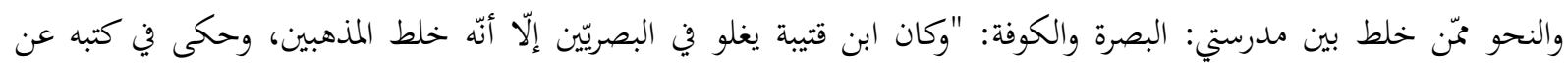

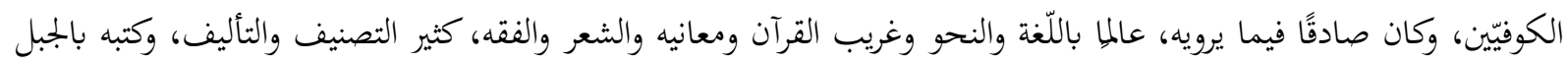

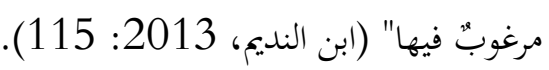


ترعرع ابن قتيبة في النصف الثاني من القرن الهجريّ الثالث، أي في فترةٍ عُرفت تاريختيّا بالعصر العبّاسيّ الثاني، وفيها عرفت

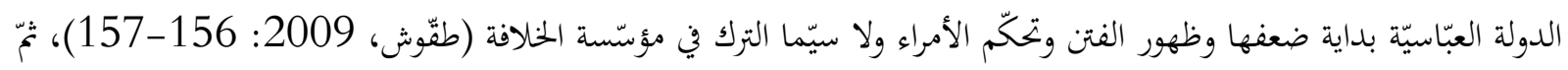

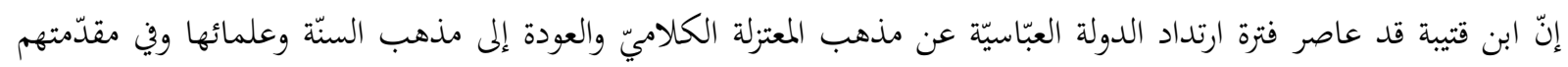

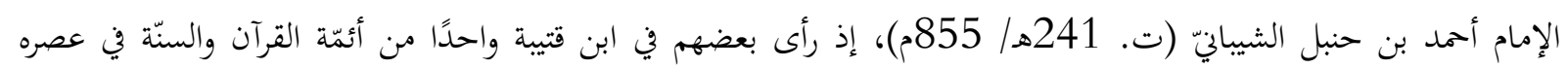

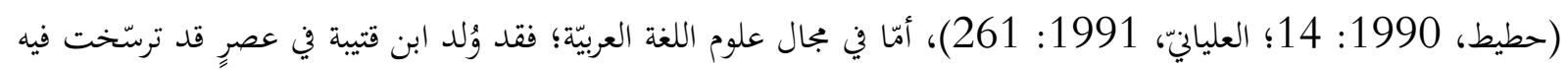

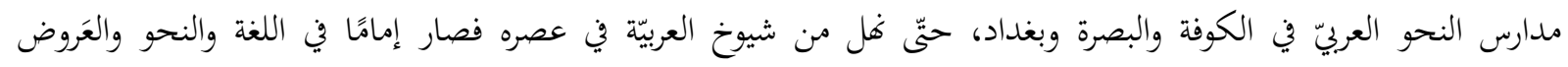
والقراءات (فضل الله، 2018: 58).

\section{كتاب أدب الكاتب}

كتابُ إرشاديٌٌ توجيهيٌٌ أدبيُّ لغويٌُ يعرض فيه كاتبه أصول الكتابة وآدابها ومعارفها، وقد ألّفه ابن قتيبة خلال مقامه في

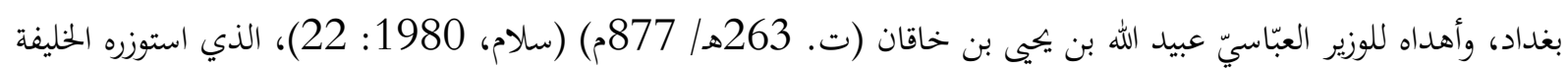

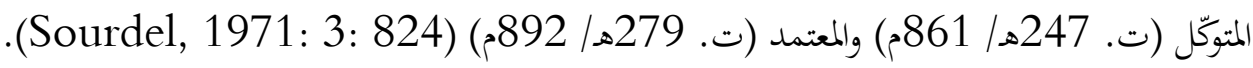

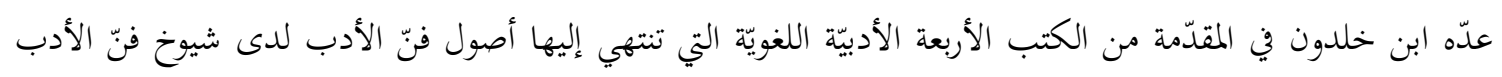

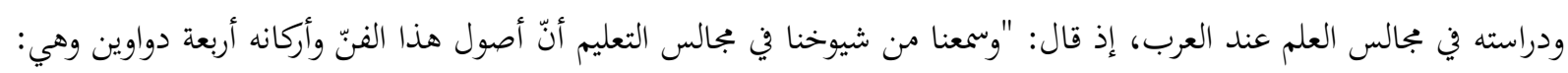

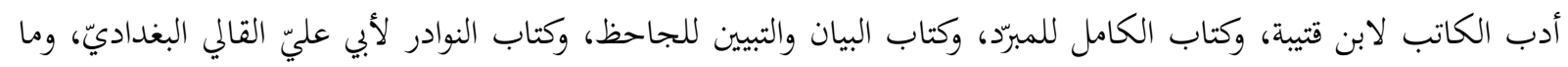

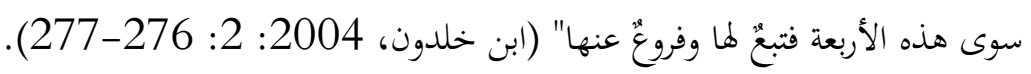
طُع كتاب أدب الكاتب عدّة طبعاتٍ تعتمد هذه الدراسة منها طبعة دار الكتب العلميّة في بيروت للعام 1988 بشرح

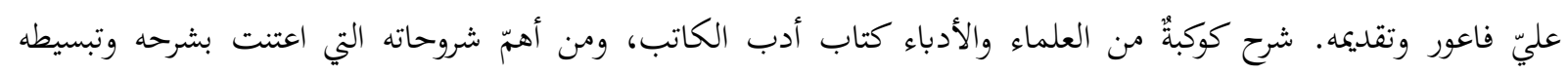
والوقوف عليه وعلى ما بتاوز فيه: الاقتضاب في شرح أدب الكتّاب لابن السّيد البطليوسيّ الأندلسيّ (ت.

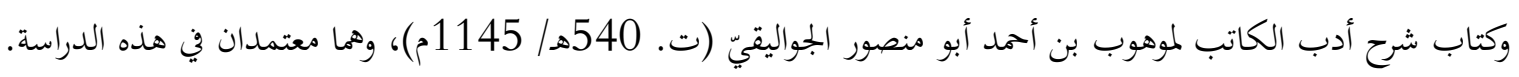

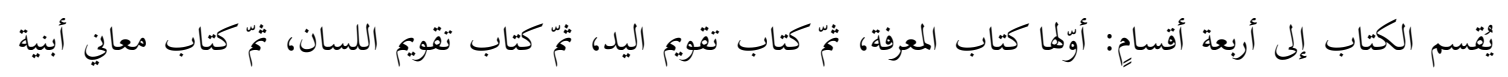

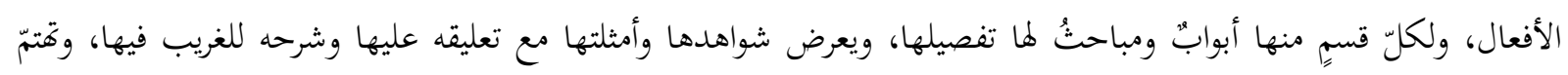

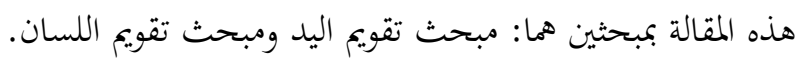

\section{الحالة اللّويّة الأدبيّة في عصر ابن قتيبة كما يصفها في أدب الكاتب}

يمكن الاعتماد عند وصف حالة اللغة العربيّة في عصر ابن قتيبة على ما أورده في مقدّمة كتابه أدب الكاتب، والتي اعتبرها

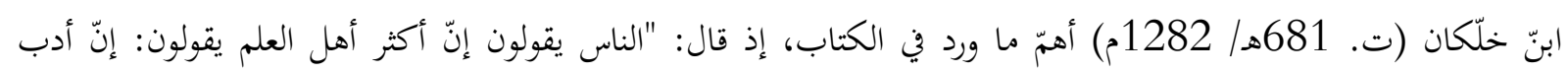

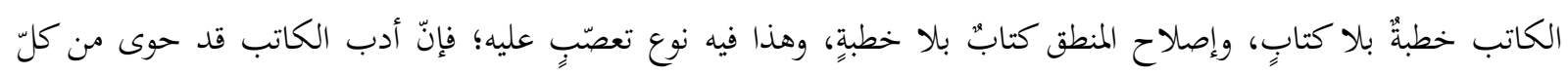

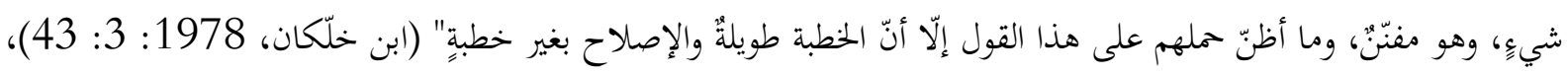

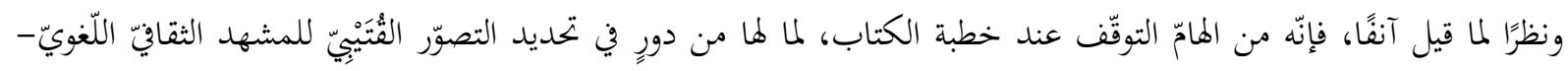

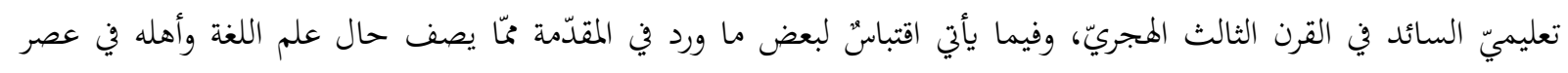

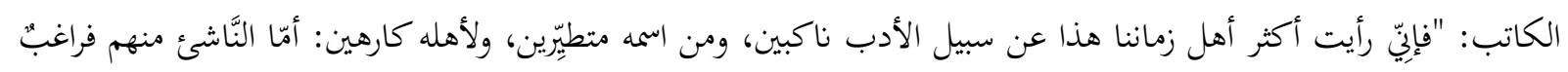

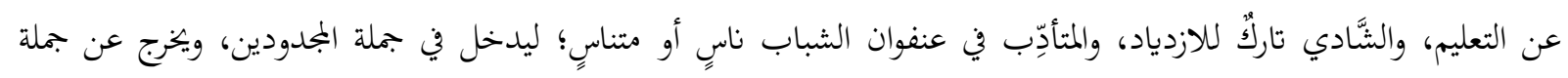


المحدودين، فالعلماء مغمورون، وبكرَّة الجهال مقموعون" (ابن قتيبة، 1988: 9)، تؤّدّد الفقرة شهادة ابن قتيبة في حال الأدب

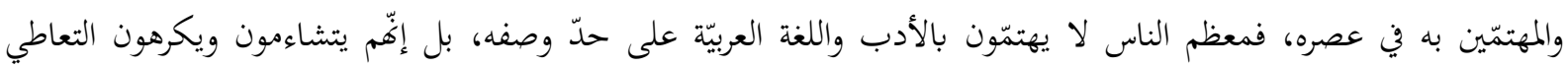

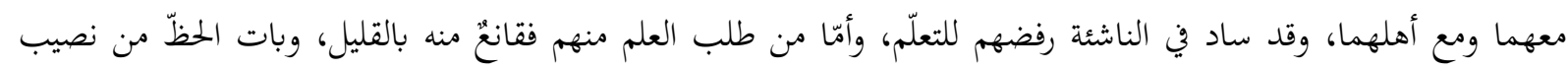

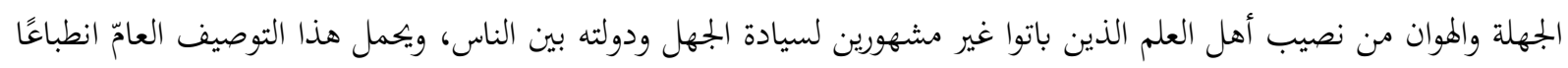

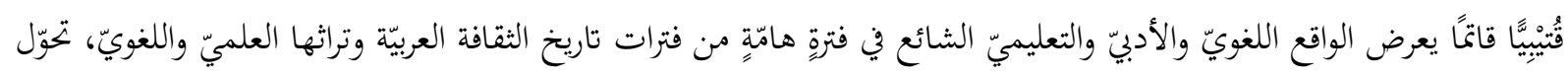

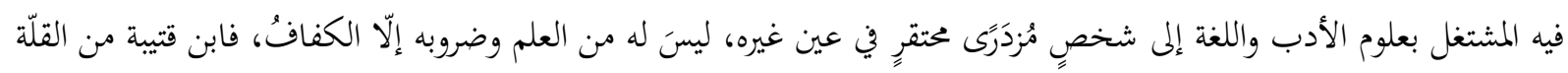

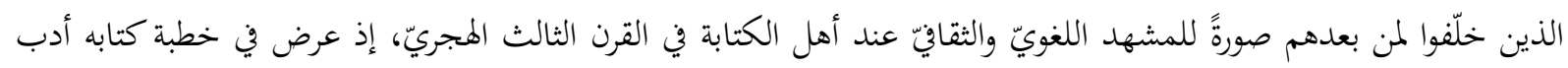

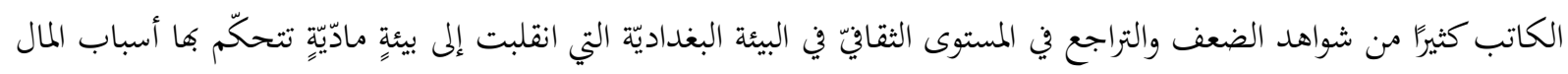

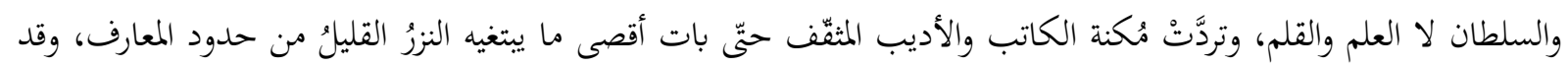

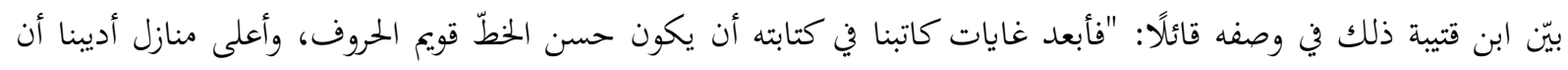

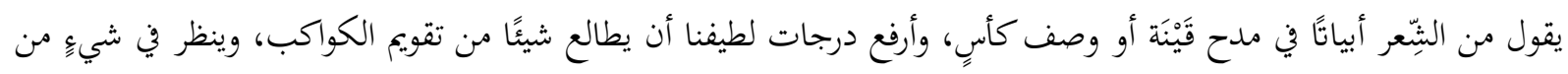

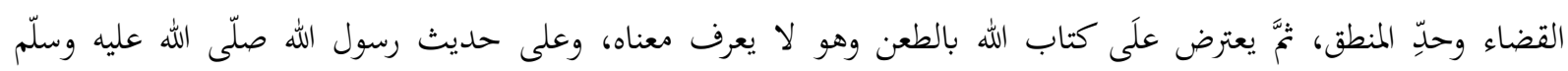

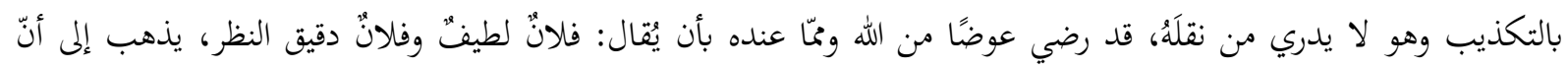

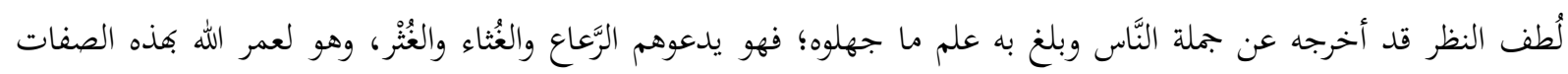

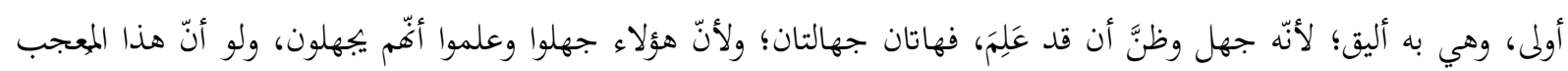

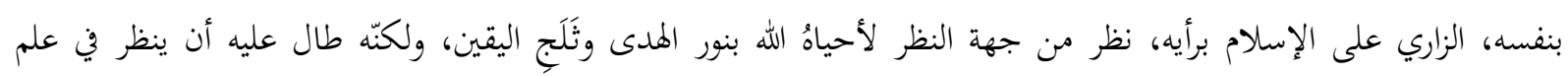

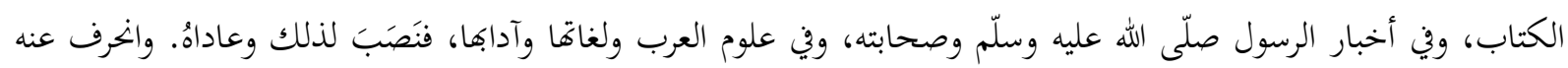

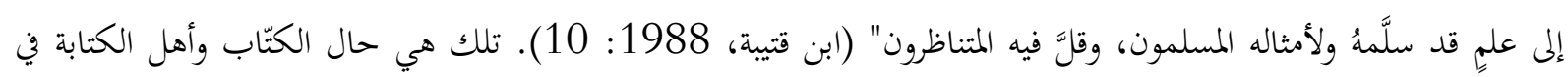

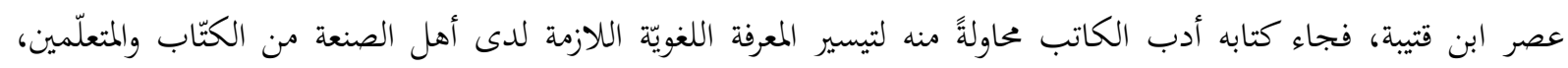

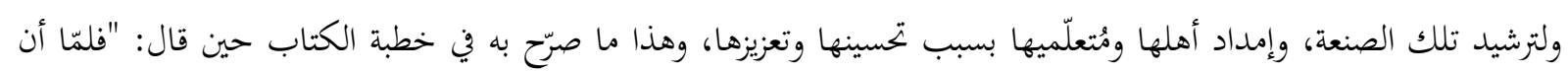

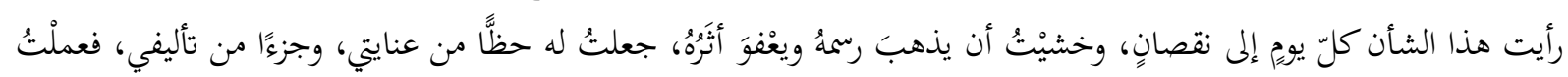

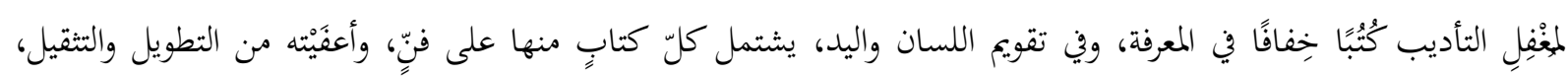

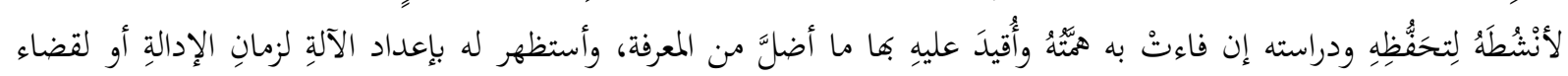

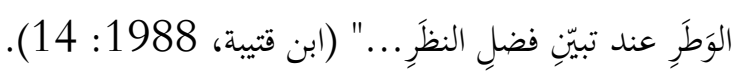

جاء باب المعرفة في كتاب أدب الكاتب محاولةً مبكّةًة لابن قتيبة لتصحيح ما وقع به الكتّاب والمتعلّمون والعامّة من أخطاءٍ

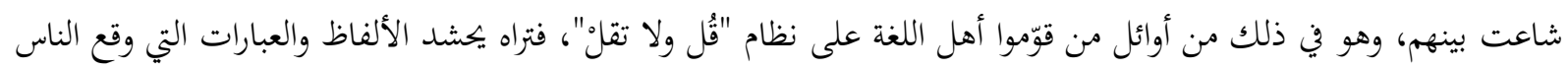

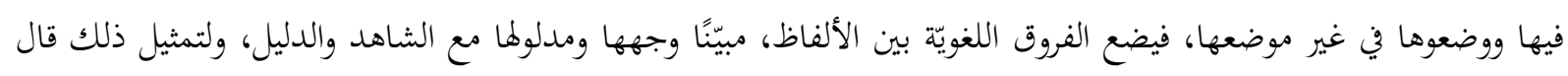

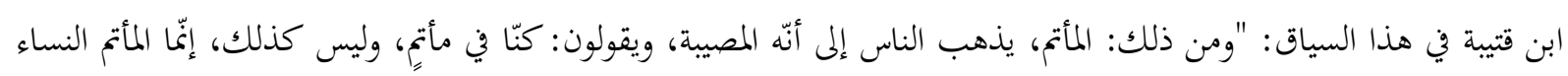

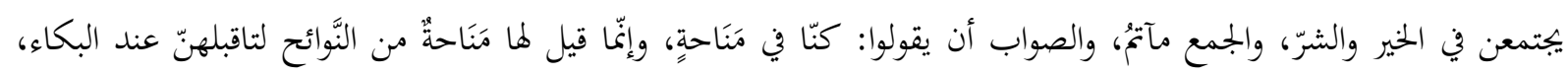

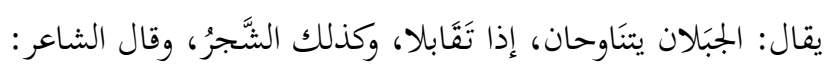

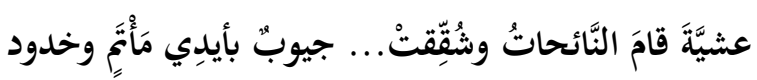
أي :بأيدي نساء، وقال آخر:

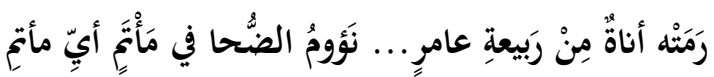

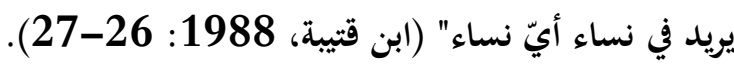


يتّضح من خلال قراءة المادّة اللغويّة في كتاب باب المعرفة أنّ ثمّة خلطًا كبيرًا عند الناس والكتّاب بين ألفاظٍ ومعانٍ تعكس تدنيًّا في تحديدها ومعرفة مدلولاتحا على النحو اللغويّ والمعجميّ السليم. يتطرّق ابن قتيبة في كتاب المعرفة إلى الكثير من القضايا اللّغيّة على غرار: القوالب المزدوجة المستخدمة في اللّغة العربيّة، باب ما يستعمل من الدعاء في الكلام، تأويل كلامٍ مستعملٍ عند العرب يشرح خلاله الكثير من العبارات الشائعة والتي يساء

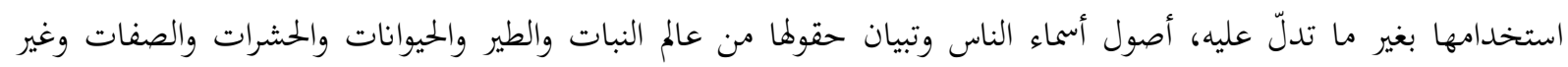

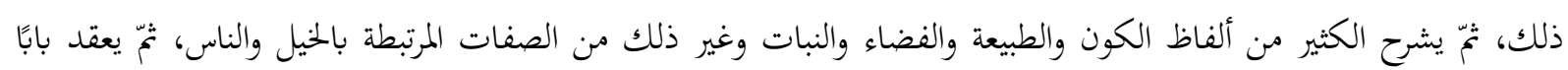

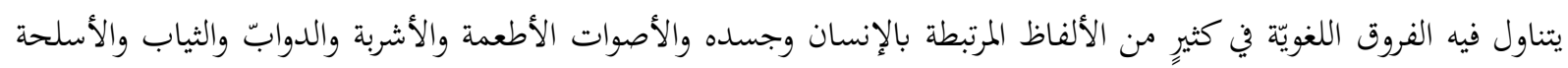

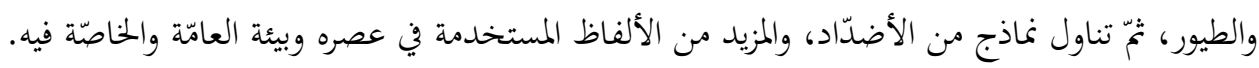

\section{مبحث كتاب تقويم اليد}

يصبو الكتاب إلى تيسير قواعد الكتابة والإملاء للمتعلّمين وأهل الكتابة؛ كي لا يقعوا في أخطاءٍ مردّها الجهل بأصول

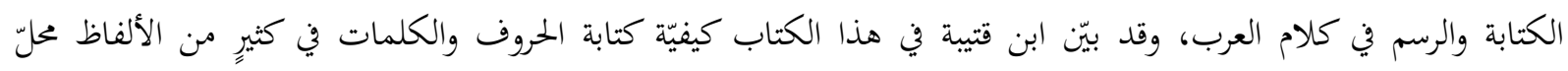

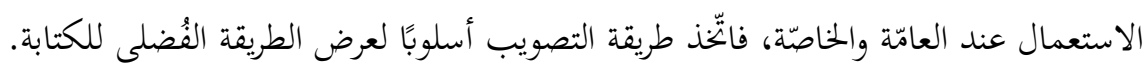

يتناول الكاتب في هذا الباب عدّة مسائل يهدف من خلالها إلى تقويم الكتابة وطرائقها، ومن أبرز مباحثه: حذف حروفٍ

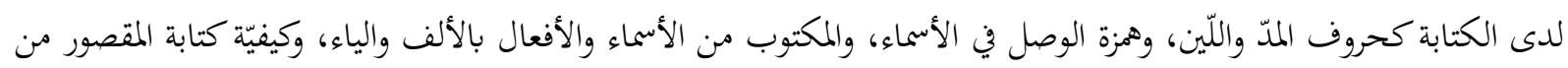

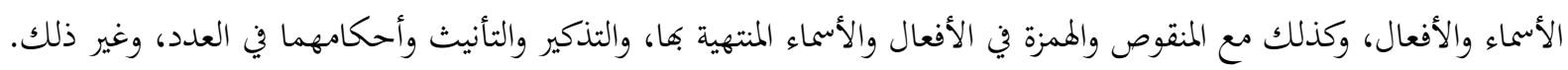
يستهلّ ابن قتيبة هذا الفصل من كتابه بعرضه قاعدةً لغويّة أصوليّةً يمهّد من خلالما لعرض التفاصيل والشواهد التي تتبع

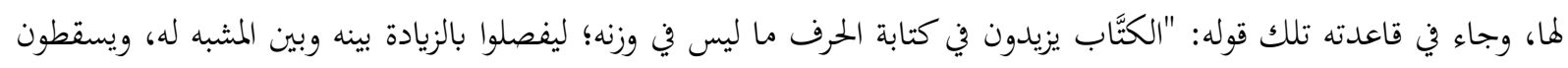

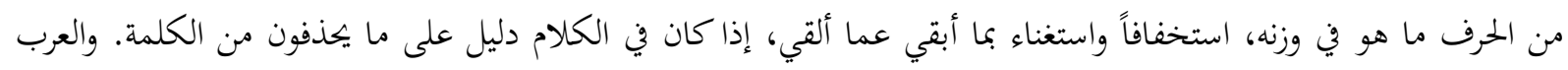

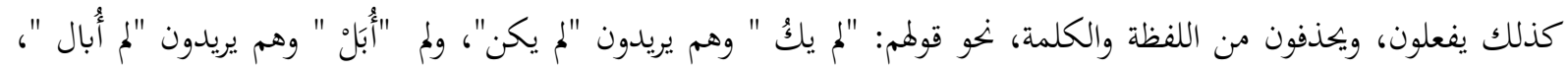

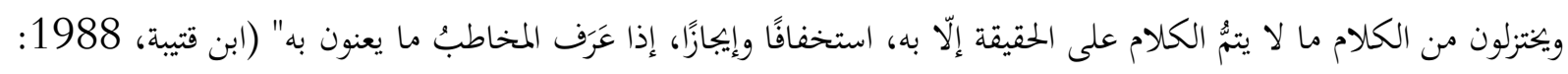

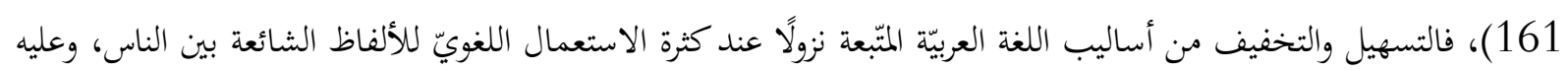
يعرض ابن قتيبة شواهده في الكتاب، ومن أمثلة ذلك تمثيلاً لا حصرًا: - كيفيّة كتابة "باسم الله": "تكتب "بسم الله " إذا افتتحت بها كتابًا أو ابتدأت بها كلامًا بغير ألفٍ؛ لأفّا كثرت في هذه

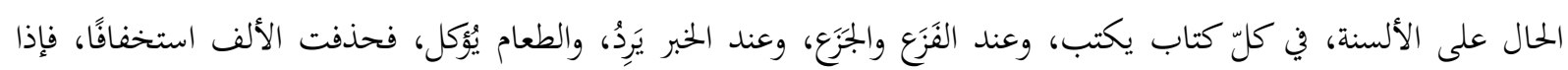

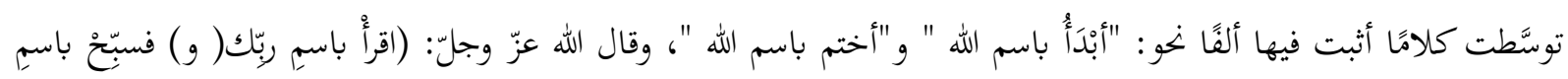

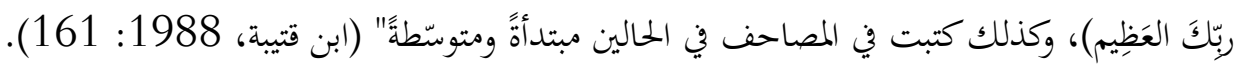
- كيفيّة كتابة الأفعال التي تبدأ بهمزة الوصل التي تليها في حروفها الياء والواو، فيعرض القاعدة من خلال الشاهد، وفي

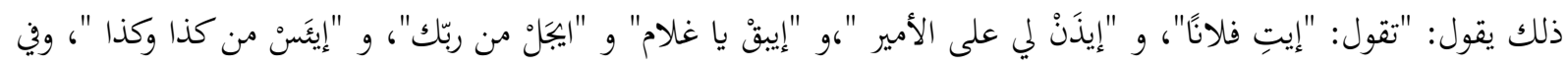

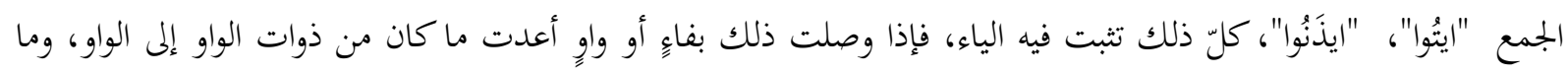

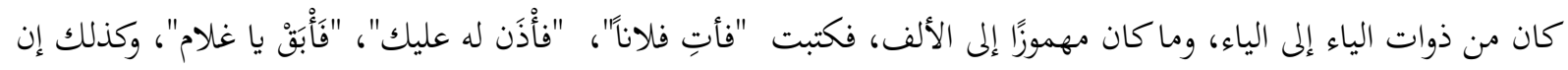

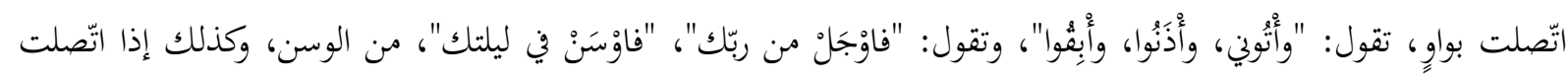

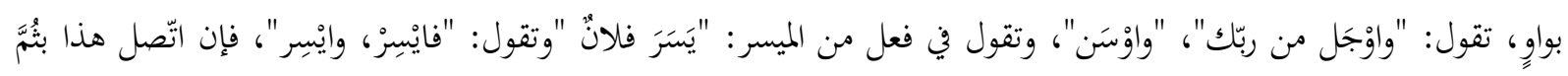




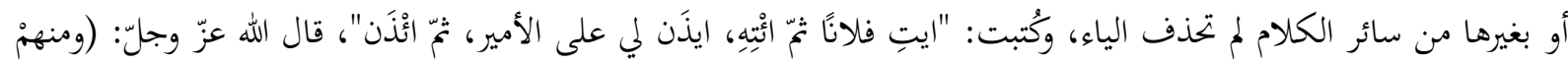

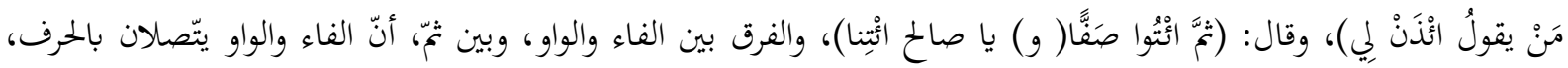

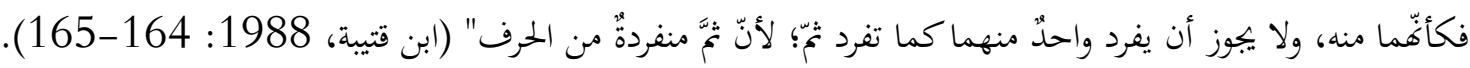
- كيفيّة كتابة الأسماء الأعجميّة وغير الأعجميّة التي فيها ألف: "تحذف الألف من الأسماء الأعجميّة نحو: إبراهيم،

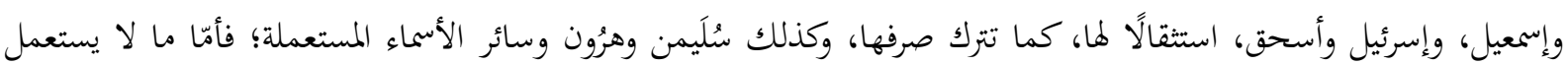

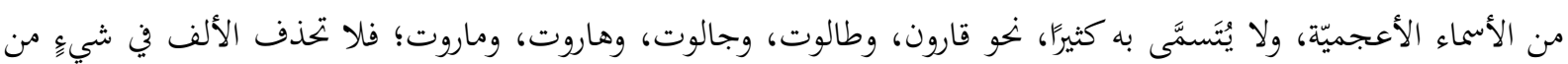

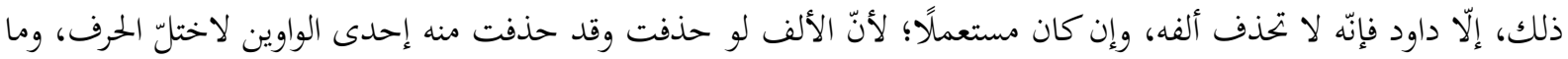

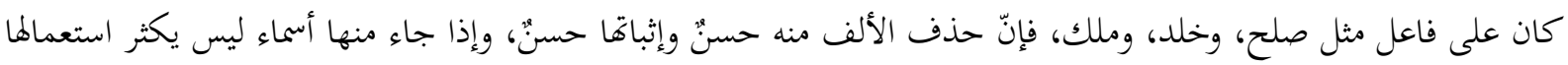

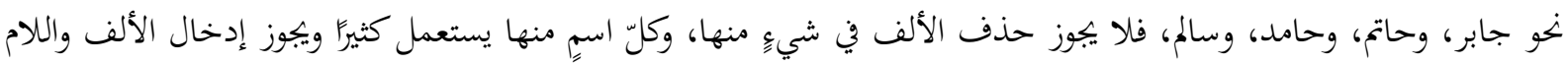

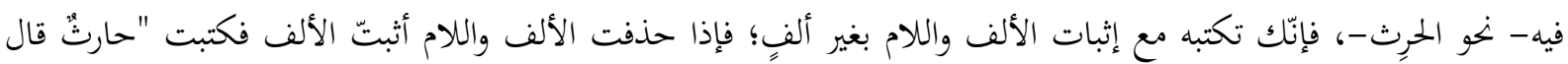

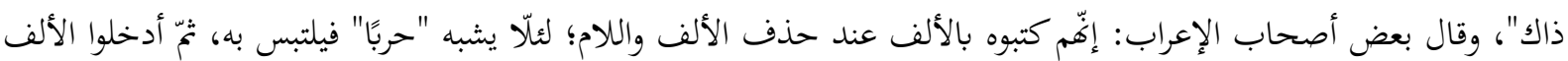

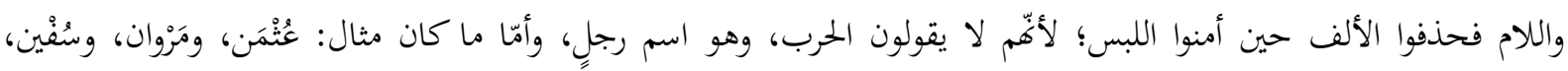

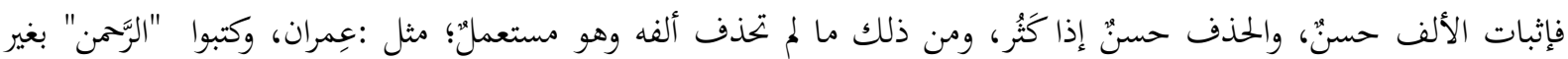
ألفٍ حين أثنتوا الألف واللام، وإذا حذفت الألف واللام فأحبُّ إليَّ أن يعيدوا الألف فيكتبوا لرَّمَّمَان الدنيا والآخرة"، وأمّا شيطان ودِهقان فإنبات الألف فيهما حسنُ، وكان القياس أن يكتبوهما إذا دخلت الألف واللام فيهما بغير ألفٍ، إلّا أنّ الكتَّاب

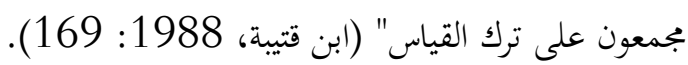
يعالج ابن قتيبة الكثير من القضايا الصرفيّة والإملائيّة المامّة والضروريّة للمشتغلين بالكتابة وشؤونها، وليس ببعيدٍ أنّه قد أورد

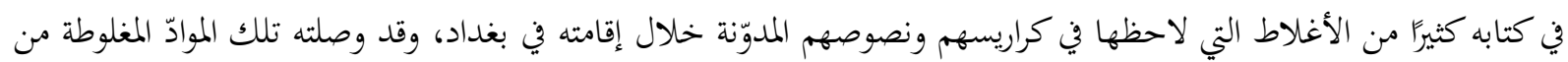
خلال تدريسه وعمله اليوميّ آنذاك.

\section{مبحث كتاب تقويم اللسان}

اهتمّ ابن قتيبة في هذا الباب بمعالجة اللُّحون اللّغيّة التي انتشرت في عصره بين المشتغلين بالكتابة، وقد انصرف في ذلك

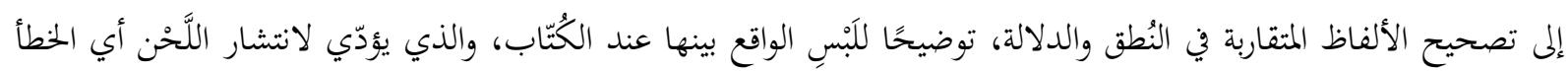

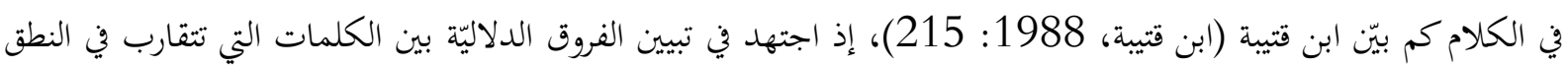

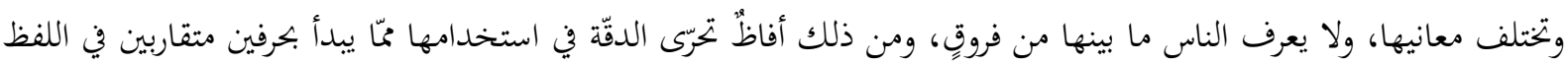

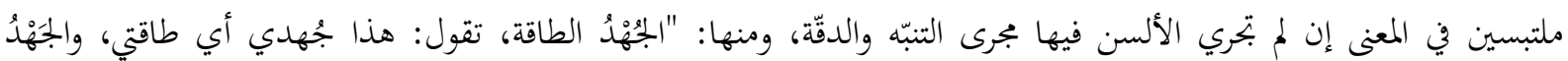

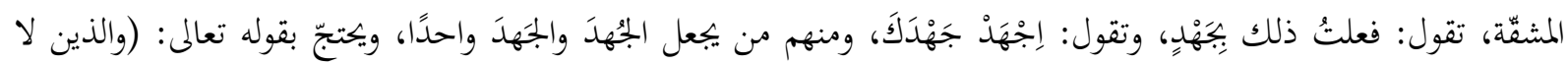

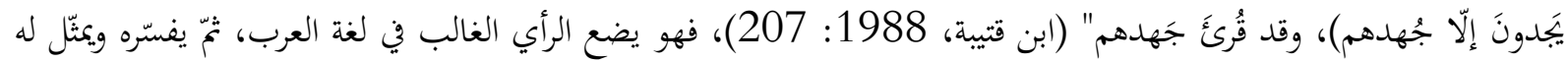

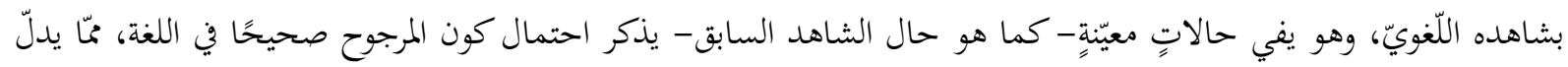

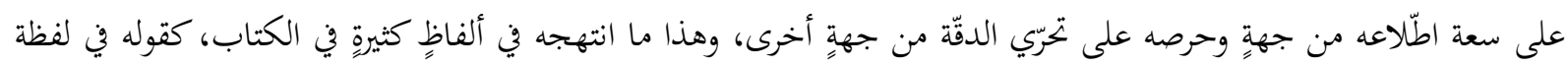

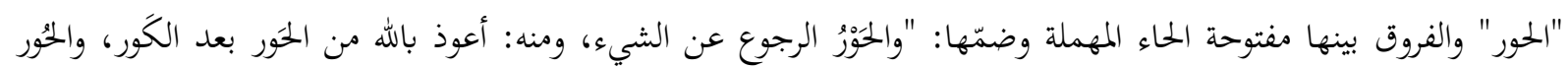
النقصان، قال الشاعر:

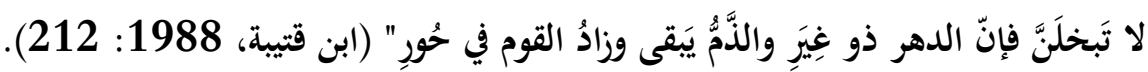


بوّب ابن قتيبة أصناف اللَّحن الواقع في الألفاظ الشائعة واستخداماتما عند الناس في أبوابٍ، وكان منهجه في ذلك توزيع

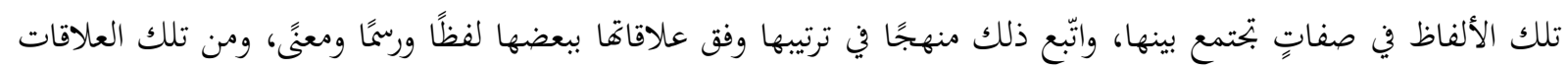

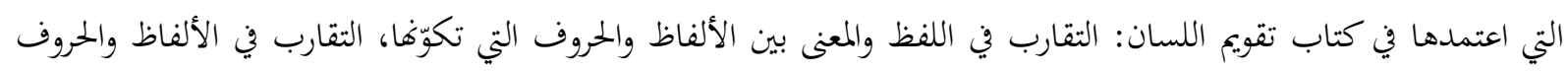

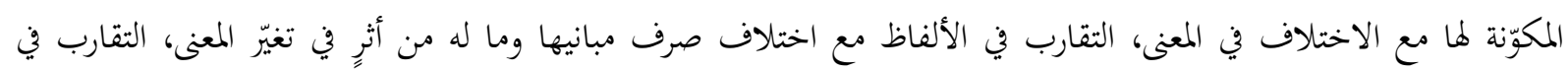

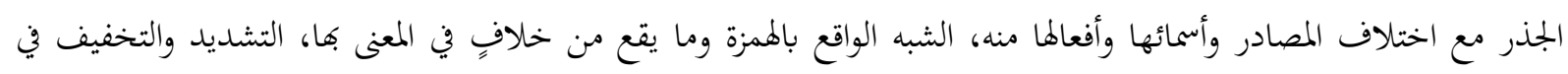
حروف الألفاظ وما يطرأ عنه من اختلافٍ في المعنى، التحريك والتسكين في حروف الألفاظ المشتركة وما يفرزه من اختلافٍ في في فئل المعنى.

يعالجُ ابن قتيبة في كتاب تقويم اللسان ظواهر اللحن الشائعة من خلال ضبط بعض القواعد اللفظيّة والإملائيّة بغية

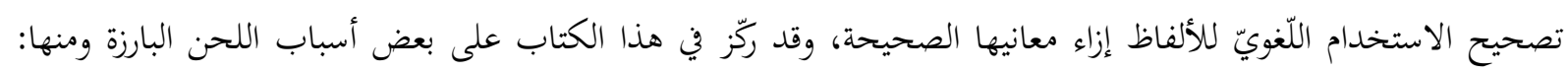
التصحيف، التحريك والتسكين، الهمز والتخفيف، التضعيف والتخفيف، وهي من عوامل دخول العامّة في كثيرٍ من الأخطاء واللحن واللبس الحاصل في اللغة العربيّة في عصره.

حاول ابن قتيبة تصحيح العديد من الأبنية اللغويّة التي أفسدها اللحن المتفشّي في عصره، وأسهم في ضبطها صرفيَّا

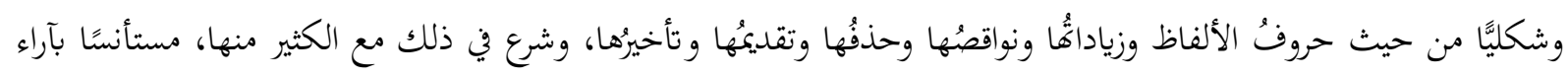

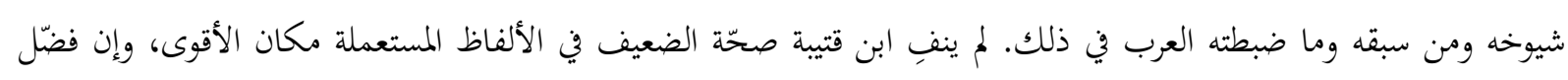

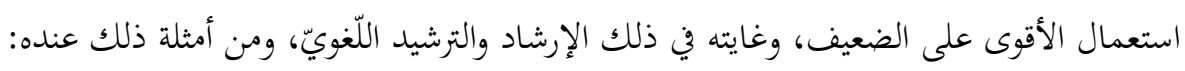

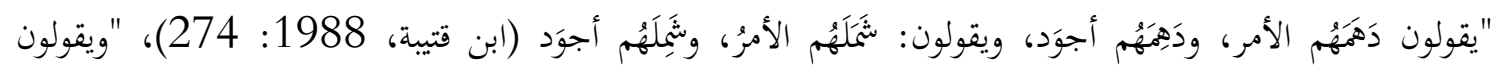

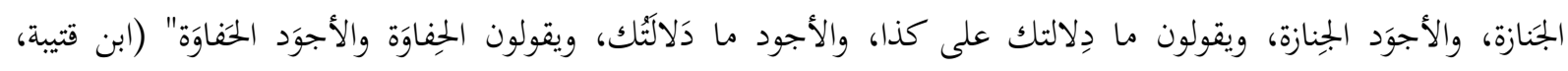

ما يقدّمه ابن قتيبة من موادّ لغويٍّ سريعةٍ مباشرة يعكس توجّهه الإرشاديّ المنهجيّ في الكتاب برمّته، فهو لا يعدو كونه

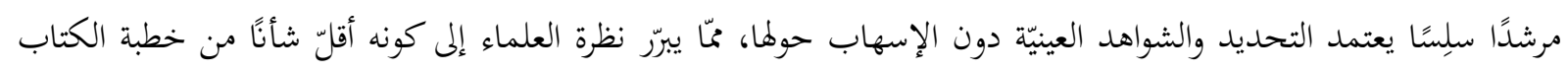
التي تتّجه نخوًا يعتمد العرض والتبرير والتوسعة في القضيّة. يدلّ منهج ابن قتيبة في كتابه ومحتواه اللّغويّ على بقاء النصص القرآيّ والشّعُعر العربيّ وحدةً لغويّةً محكمةً يحتكم إليها

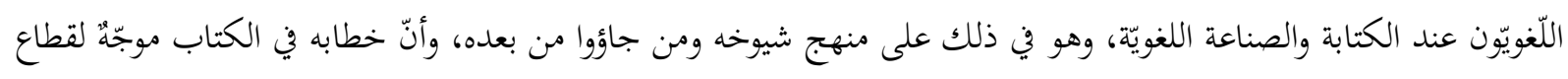

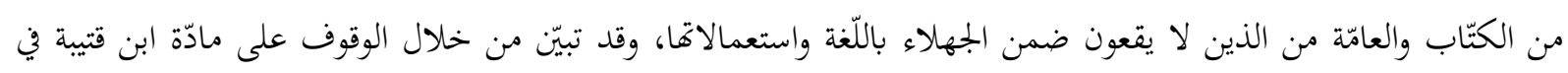

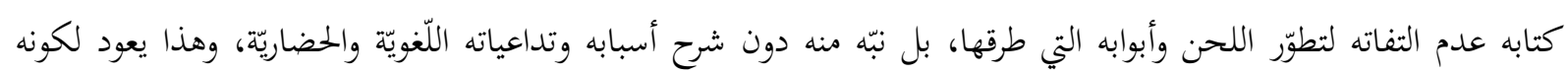

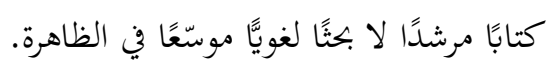

أضفت ثقافة ابن قتيبة اللّغيّة الواسعة في كتابه أدب الكاتب عمومًا وكتابي: تقويم اليد وتقويم اللسان فيه بنحوِ خاصِّ،

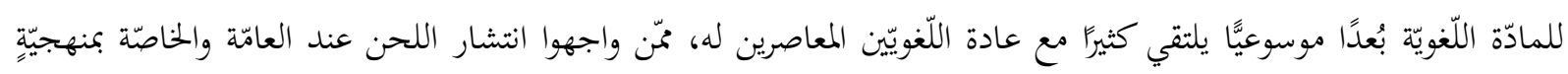

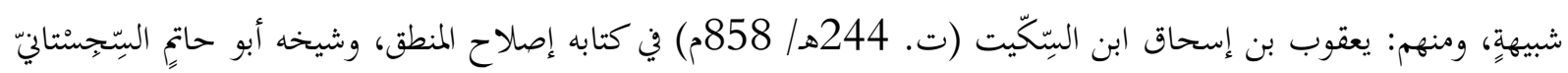

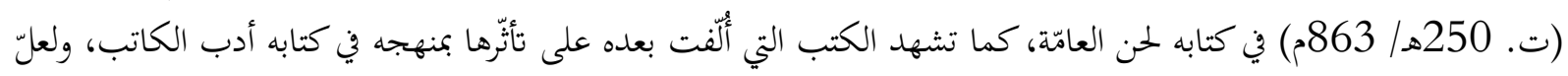

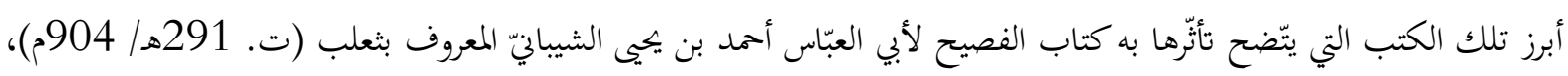

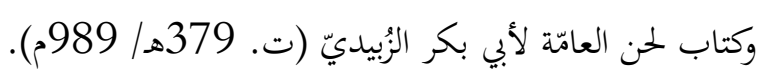


ليس من شاكِّ أنّ كتاب أدب الكاتب قد شكّل موجِهًا مفيدًا للكتّاب والعامّة من الذين غلوا منه وثقِّوا لسافم ولغتهم

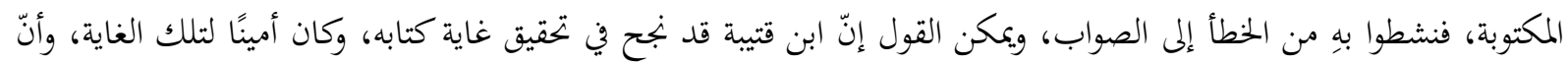

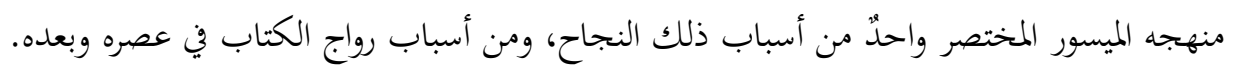
شرّاح أدب الكاتب

برز من شرّاح كتاب أدب الكاتب لابن قتيبة اثنان، أحدهما في المشرق، وهو أبو منصورٍ الجواليقيّ (ت. 540هـ/

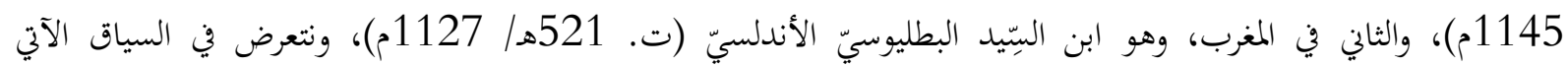

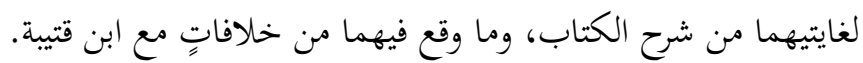

\section{كتاب شرح أدب الكاتب لموهوب بن أحمد أبي منصورٍ الجواليقيّ (ت. 540هـ 1145م)}

يحدّد أبو منصورٍ غايته من شرح أدب الكاتب لابن قتيبة في مقدّمة شرحه، ويذكر أنّه يقصد من ذلك شرح خطبة

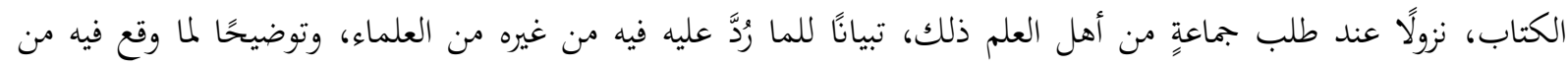

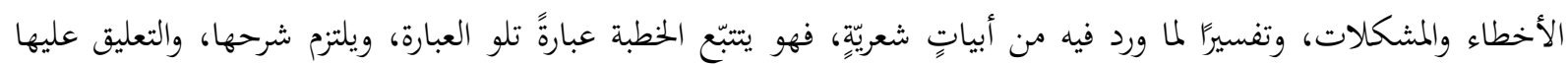

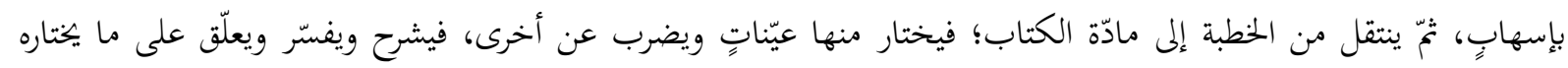

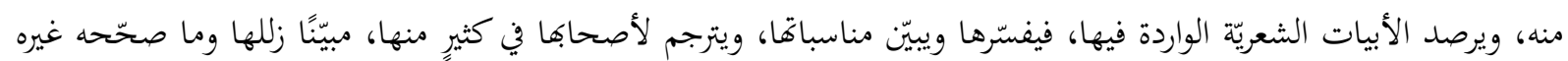
فيها (الجواليقيّ، 1995، 192: 1 1). وجّه الجواليقيّ نقده لكتاب أدب الكاتب من خلال اعتراضاته على بعض ما ورد فيه، ولا سيّما في المسائل المرتبطة

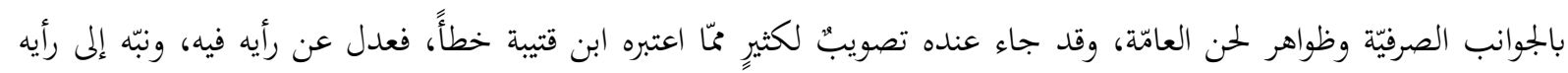

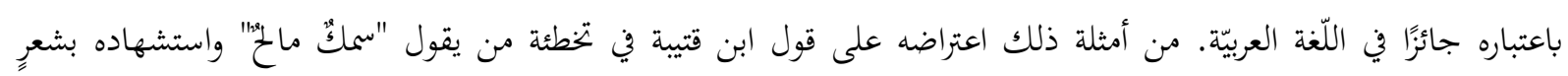

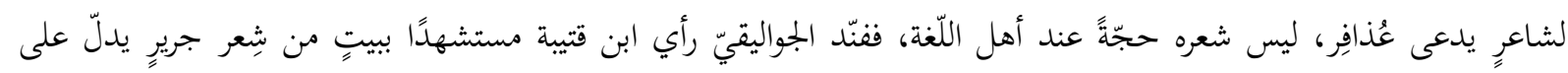

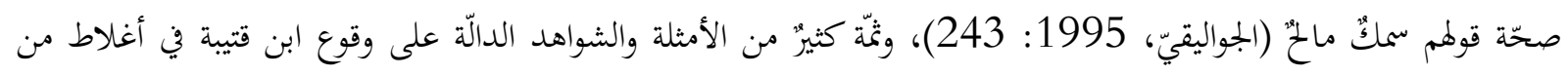
وجهة نظر من كانوا من بعده وشرحوا كتابه.

\section{كتاب الاقتضاب في شرح أدب الكتّاب لابن السِّيد البطليوسيّ الأندلسيّ (ت. 521هـ/ 1127م)} يذهب الشارح في هذا الكتاب إلى انتقاء مواضع معيّنة من مادّة كتاب أدب الكاتب لابن قتيبة، ويهتمّ فيما وقع فيه

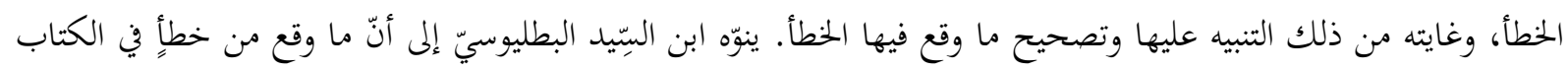

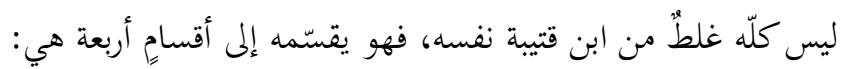
1. مواضع أخطأ فيها ابن قتيبة فينبّه عليها وعلى خطأه فيها.

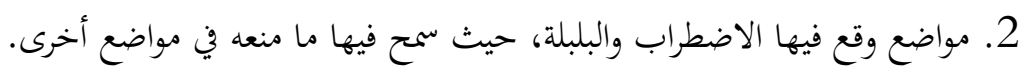

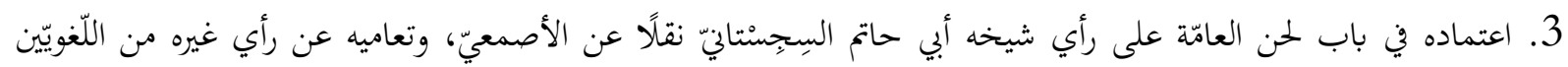
الكبار متّن لا يتّفقون معه؛ مّمّا يوهن قوله. 4. مواضع وقع فيها الغلط بسبب الناقلين لمادّة الكتاب لا لمؤلّفه.

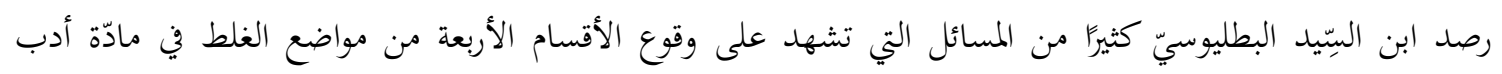

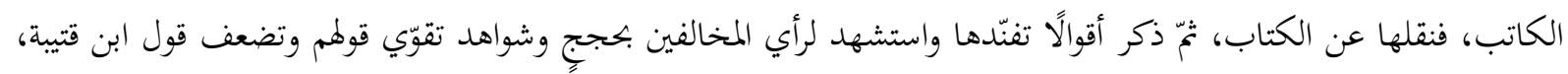

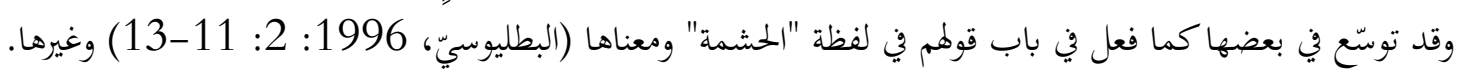


جاء منهج البطليوسيّ واضحًا في تعاطيه مع ما وقع في أدب الكاتب من أغلاطِ، إذ عرض قول ابن قتيبة مقتبسًا، ثمّ أنّا عرض آراء غيره مع ذكر أسمائهم، ثمّ استأنس بشاهدٍ أو أكثر يدعم رأيهم ويفنّد رأي ابن قتيبة في المسألة.

\section{استنتاجات الدراسة}

- ينضمّ ابن قتيبة إلى كوكبة اللغيّين العرب الذي حاولوا بجهودهم اللغويّة خلال القرن الثالث الهجريّ/ التاسع الميلاديّ أن ينهضوا باللغة العربيّة وعلومها من خلال تأليف الكتب الموجّهة الهادفة والتي تنفع الخاصّة والعامّة على حلدٍ سواء. - اجتهد ابن قتيبة في مواصلة مسار شيوخه وفيهم السِحِستتانيّ والرياشيّ وغيرهما من علماء اللغة، فاهتمّ بالتببيه على وجوه

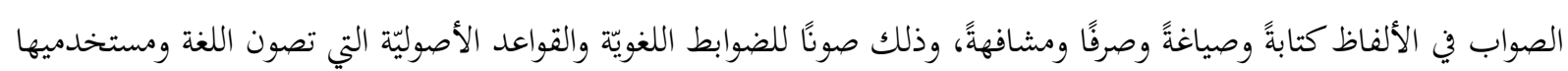

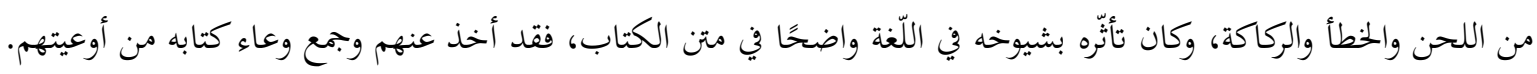
- اعتمد ابن قتيبة في كتابه أدب الكاتب على مقاييس لغويّة عمادها المشهور عند العرب ولغتهم، فاعتمده في تصويبه للأخطاء

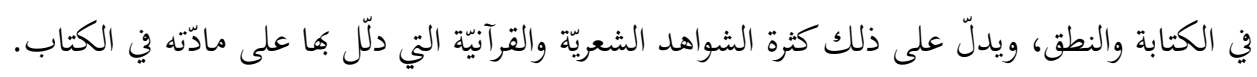
- يعتبر ابن قتيبة من المتشدّدين في وجوه قَبول الصواب ودفِع الخطأ، فهو من الذين يُقْبِلونَ على الأفصح المشهور، ويدَعونَ ما عَداهُ، بل يعتبرونَهُ لحنًا. - وجّه ابن قتيبة كتابه ومادّته فيه لشريحة الكتّاب الخاملين المتهاونين في اللغة وضوابطها، فجاء كتابه مرشلًا لهم ودليلًا عمليَّا يعينهم في صناعتهم. - يبدو من خلال مادّة كتاب أدب الكاتب لابن قتيبة أنّ المشهد الثقافيّ في عصره يعاني من ضعفٍ ووَهَنٍ أسبابه مرتبطةٌ بميل العامّة والخاصّة عن طلب العلم بطريقهِ وسبلهِ العلميّة السديدة. - تستنتج الدراسة أنّ ابن قتيبة قد يسّر في كتابه لجمهوره ما أمكنه من أسباب الشرح الموجز والمقارنات السهلة كي يجعلها مادّةً

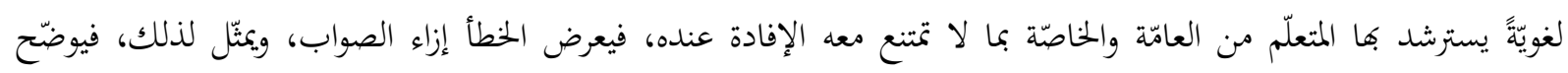
الشيء بضدّه إذا لزم الأمر.

- سعى شارحا كتاب أدب الكاتب: البطليوسيّ في الاقتضاب والجواليقي في شرح أدب الكاتب إلى تبيان وجوه ما جاء في

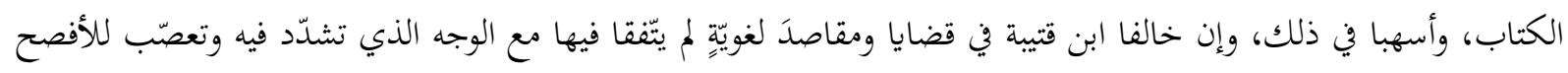

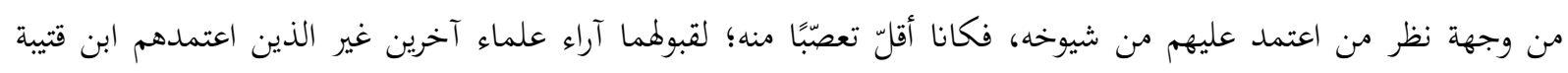
مرجعًا في آرائه، فعمدا إلى تبيان الصواب الذي ظنّه ابن قتيبة غلطًا؛ لاقتصاره على مذهب شيوخٍ وإضرابه عن رأي غيرهم. 
البَطليوسيّ، ابن السِّيد عبد الله بن محمّد. (1996). الاقتضاب في شرح أدب الكُتّاب. تحقيق: مصطفى السقّا وحامد عبد المجيد. القاهرة: مطبعة دار الكتب المصريّة.

الجواليقيّ، موهوب. (1995). شرح أدب الكاتب. تحقيق: طيبة حمد بودي. جامعة الكويت: قسم اللّغة العربيّة.

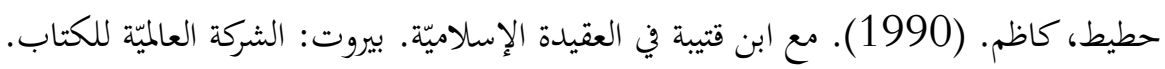
ابن خلدون، عبد الرحمن. (2004). مقدّمة ابن خلدون. تحقيق: عبد الله محمّد الدرويش. دمشق: دار البلخي. الذهبيّ، الإمام حممّد بن أحمد بن عثمان. (1983). سير أعلام النبلاء. تحقيق: علي أبو زيد. بيروت: مؤسّسة الرسالة. سلام، محمّد زغلول. (1980). نوابغ الفكر العربيّ: ابن قتيبة. القاهرة: دار المعارف.

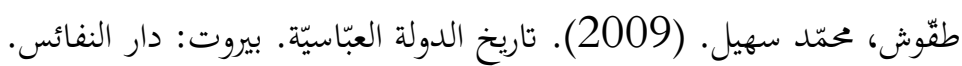
العليانيّ، عليّ بن نفيع. (1991). عقيدة الإمام ابن قتيبة. الطائف: مكتبة الصدّيق.

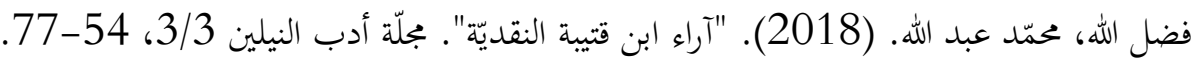

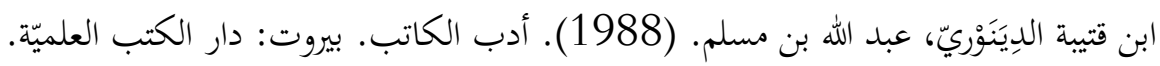

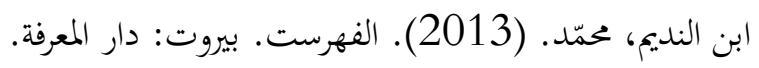

Sourdel, D. “Ibn Khākān”. Encyclopaedia of Islam. Second Edition, 1971, 3: 824. 